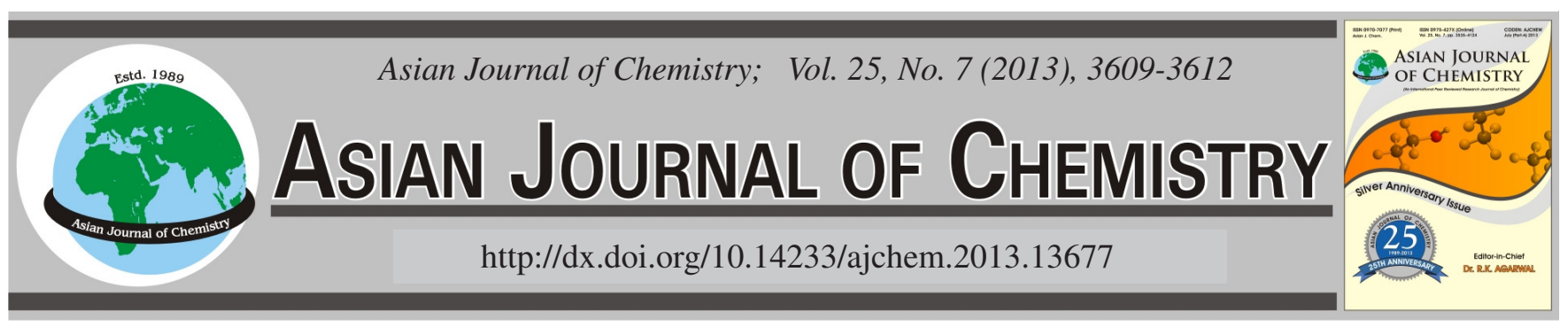

\title{
Ionic Strength Effect on Copper(II) Biosorption by Folium camelliae Biomass: Equilibrium Study and Dynamic Modelling in Membrane Reactor
}

\author{
Jun-JiNG GUO* and WEN-BIN CHEN
}

Department of Chemical Engineering, Huaihai Institute of Technology, Lianyungang 222005, P.R. China

*Corresponding author: Tel: +86 130 56050082; E-mail: lygcwb11@163.com

(Received: 29 February 2012;

Accepted: 7 January 2013)

AJC-12659

\begin{abstract}
The removal of heavy metals by adsorption using biomaterials has been widely reported in the literature. The biosorption of copper(II) by the Folium camelliae was investigated a function of initial lead concentration, biosorbent concentration,temperature and $\mathrm{pH}$, contact time and temperature was carried out. The nature of the possible biosorbent and metal ion interactions was examined by the FTIR technique. Adsorption equilibrium was observed within $1 \mathrm{~h}$. Adsorption equilibrium data were well described by Langmuir isotherm model. The maximum adsorption capacity was $75.20 \mathrm{mg} \mathrm{g}^{-1}$ at $318 \mathrm{~K}$ and $\mathrm{pH}$ 4.4. From the Dubinin-Radushkevich model, the mean free energy was calculated as 12.1-15.8 $\mathrm{kJ} \mathrm{mol}^{-1}$ ranging from $285-318 \mathrm{~K}$, indicating the adsorption was taken place by chemical ion-exchange. Thermodynamic parameters $\left(\Delta \mathrm{G}^{\circ}, \Delta \mathrm{H}^{\circ}\right.$ and $\left.\Delta \mathrm{S}^{\circ}\right)$ were also evaluated. These parameters showed that the adsorption process was feasible, spontaneous and endothermic under studied conditions. Desorption experiments indicated that the fixed lead on the biomass was stable in common solutions except acid media. These results announced an excellent adsorption material and also strongly suggest us that tea plant must be kept away from lead pollution.
\end{abstract}

Key Words: Adsorption, Folium camelliae, Copper(II).

ᄂ ---------------------------------$\lrcorner$

\section{INTRODUCTION}

Increasing industrialization brings with it the problems of removal of undesired and possibly toxic metals from chemical process effluent. Several toxic metals, which present in the waste water, such as cadmium, lead, zinc and copper cannot be degraded by biological and chemical processes ${ }^{1}$. The discharge of non-essential nature of these metals into environment posses a severe threat to human and living creatures. In this condition, these metals are highly toxic non-essential elements that serve no known biological function. In addition, these metals tend to bioaccumulate and biomagnify in our food chain,which could be eventually consumed by human ${ }^{2}$.

Traditional technologies for removal of heavy metal, including ionic exchange and precipitation are frequently inefficient and or expensive when applied for removal of metal ions in low concentrations. Several treatment processes have been developed over the years to remove heavy metals dissolved in the wastewater, such as chemical precipitation, chemical oxidation and reduction, ion exchange, solvent extraction and membrane filtration. However, these methods are either inefficient or expensive when heavy metals exist in low concentrations. Additionally, these methods may also create secondary pollution ${ }^{1}$. Consequently, there is a dire need for new technologies or materials for heavy metal sequestration.
In recent years, many researchers have been investigating ideal adsorbents for heavy metal removal such as barley straw ${ }^{2}$, Mucor rouxii ${ }^{3}$, Antep pistachio shells ${ }^{4}$, spent grain ${ }^{5}$, Sphagnum peat $^{6}$, peanut husk ${ }^{7}$. All of these agricultural by-products have showed excellent biosorption behaviour.

Green tea originates from China. There are more than 1,600,000 hectare of $F$. camelliae gardens in China. Some scientists have done much job on various tea leaves modified or rinsed with hot water ${ }^{8,9}$. But lead pollution is unavoidable during the tea processing and experiments conducted with pretreated material makes it difficult to get raw information on the susceptibility to metal pollution of fresh tea planting. Therefore, F. camelliae without any modification was used in our study based on triple purposes: (1) to probe the potential of $F$. camelliae as a low-cost substitute for conventional adsorbents with batch experiment method and spectral analysis; (2) to gain insight into whether the quality of tea product would be contaminated by lead owing to the common water and air pollution; (3) to give suggestions to tea planting.

\section{EXPERIMENTAL}

Folium camelliae was collected from Huaguo Mountain of China. The sample was properly cleaned with deionized water, dried at $333 \mathrm{~K}$ and finally ground to pass a 100-mesh sieve. The BET surface area was determined as $1.05 \mathrm{~m}^{2} \mathrm{~g}^{-1}$ by 
nitrogen adsorption isotherms measured at $77 \mathrm{~K}$ using a $\mathrm{N}_{2}$ adsorption analyzer (Micromeritics ASAP 2020). Analytical grade reagents were used in all cases.

Batch adsorption experiments were carried out in capped conical flask $(250 \mathrm{~mL})$ at a specified temperature, by suspending $0.2 \mathrm{~g}$ of adsorbent in $100 \mathrm{~mL}$ of copper(II) solution at specified solution $\mathrm{pH}$. The suspensions were mixed on a shaker with a constant agitation speed of $120 \mathrm{rpm}$. When finished, solid was separated and the filtrate was analyzed with an atomic absorption spectrometer (TAS-990, PGENERAL, China). The amount of copper(II) sequestered was calculated using mass balance equation.

\section{RESULTS AND DISCUSSION}

FTIR analysis: The FTIR spectra (Table-1) of dried unloaded $F$. camelliae, copper(II)-loaded biomass were recorded to obtain information on the nature of possible biomass-metal ion interactions.

\begin{tabular}{ccc}
\multicolumn{3}{c}{ TABLE-1 } \\
\multicolumn{3}{c}{ FTIR ABSORPTION BANDS AND } \\
CORRESPONDING POSSIBLE GROUPS \\
\cline { 1 - 2 } Frequency $\left(\mathrm{cm}^{-1}\right)$ \\
\cline { 1 - 2 } Law & Lead(II) & \multicolumn{1}{c}{ Association } \\
\cline { 1 - 2 } biomass & loaded biomass \\
\cline { 1 - 2 } 3419.55 & 3415.78 & -OH, -NH stretching \\
2923.26 & 2924.45 & C-H stretching \\
1646.40 & 1649.26 & C=O chelate stretching, amide I band \\
1452.33 & 1454.08 & C-CH ${ }_{3}$ asymmetric stretching \\
1146.81 & 1147.60 & C-O stretching \\
1048.62 & 1066.83 & C-O stretching of carbonyl \\
\hline
\end{tabular}

A broad and strong band at $3419 \mathrm{~cm}^{-1}$ was characteristic for O-H and N-H groups. The band at $2923 \mathrm{~cm}^{-1}$ was ascribed to the asymmetric stretch of $\mathrm{CH}_{2}$ groups. The peak at 1646 $\mathrm{cm}^{-1}$ was attributed to $\mathrm{C}=\mathrm{O}$ stretching vibration. The peak at $1048 \mathrm{~cm}^{-1}$ assigned to stretching of alcoholic C-O groups on the biomass surface.

After copper(II) adsorption, $\mathrm{OH}$ stretching vibration was shifted to $3416 \mathrm{~cm}^{-1}$. The obvious shift to the lower wavenumber after adsorption suggested that chemical interactions between the metal ions and the $\mathrm{OH}$ groups occurred on the biomass surface. The $\mathrm{C}=\mathrm{O}$ peak was observed at $1649 \mathrm{~cm}^{-1}$. In addition, the peak of $\mathrm{C}-\mathrm{O}$ groups shifted to $1067 \mathrm{~cm}^{-1}$. These results indicated that the $\mathrm{O}-\mathrm{H}, \mathrm{C}=\mathrm{O}, \mathrm{C}-\mathrm{O}$ and $=\mathrm{NH}$ functional groups play a major role in binding copper(II).

Effect of pH: The $\mathrm{pH}$ dependence of metal adsorption is largely related to the surface functional group in the adsorbent and metal solution chemistry ${ }^{10}$. Fig. 1 shows the effect of $\mathrm{pH}$ on copper(II) removal. The results indicated that the adsorption quantity increased from $30.73-43.70 \mathrm{mg} \mathrm{g}^{-1}$ as the $\mathrm{pH}$ value ranged from 2.8-4.4. Similar observations have been earlier recorded. This was because the point of zero charge $\left(\mathrm{pH}_{\mathrm{ZPC}}\right)$ for $F$. camelliae was $c a$. 3.3. Polar functional groups, acrylamide, amino and carboxyl were protonated at lower $\mathrm{pH}$ and the electrostatic force of repulsion was inimical to the adsorption. In the $\mathrm{pH}$ range of 2.8-4.4, adsorbent surfaces were more negatively charged and the repelling forces diminished when the $\mathrm{pH}$ values increased.

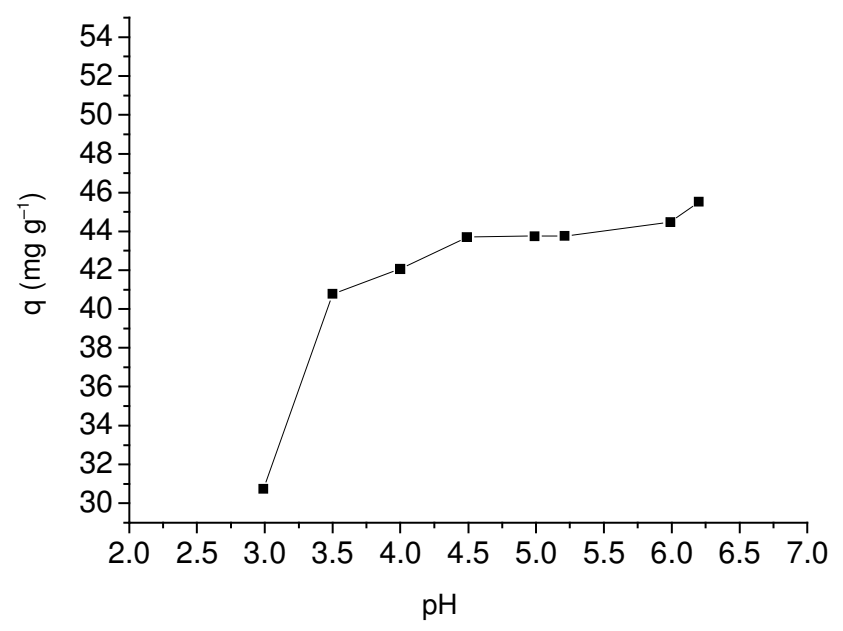

Fig. 1. Effect of $\mathrm{pH}$ on the adsorption of copper(II) onto F. camelliae

Chemical species are also possible mechanism affecting the adsorption. In this study, maximum adsorption is observed at $\mathrm{pH} 5.5$, which might be partly due to the hydrolysis of copper(II), leading to the formation of copper(II)-OH $\mathrm{OH}^{+}$. Larger radii and less positive charge made the acting force between the complexes of copper(II) and negative charged adsorbent weakened. Hence, the retention would slowdown.

Effects of contact time and temperature: Fig. 2 indicates the effect of contact time on the adsorption process. It can be seen that the adsorption capacity rapidly increased in the first $0.5 \mathrm{~h}$ after which adsorption capacity gradually approached equilibrium. In general, $c a .96 .5 \%$ of the total copper(II) was removed within $1 \mathrm{~h}$. Therefore $1 \mathrm{~h}$ was deemed suitable to establish equilibrium in subsequent experiments.

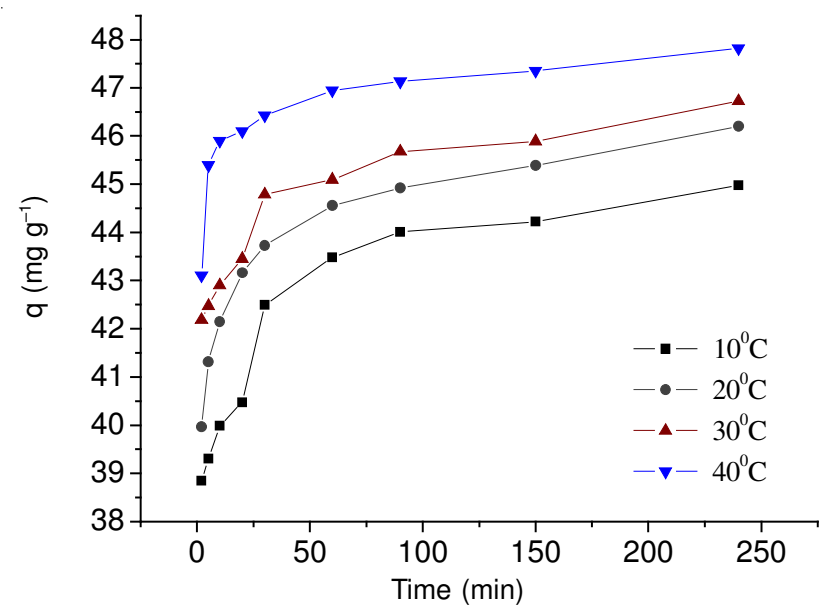

Fig. 2. Effect of contact time on copper(II) adsorption at various temperatures

Fig. 2 also showed that higher temperature favored the adsorption process, indicating the endothermic nature of copper(II) adsorption onto $F$. camelliae biomass.

Adsorption isotherm: The equilibrium concentration dependence data (Fig. 3) was tested using different adsorption isotherm models in order to develop an equation which can accurately represent the results and can be used for design purpose. Several isothermal equations are available for analysis. In this study, Freundlich, Langmuir and DubininRadushkevich (D-R) models were employed. 


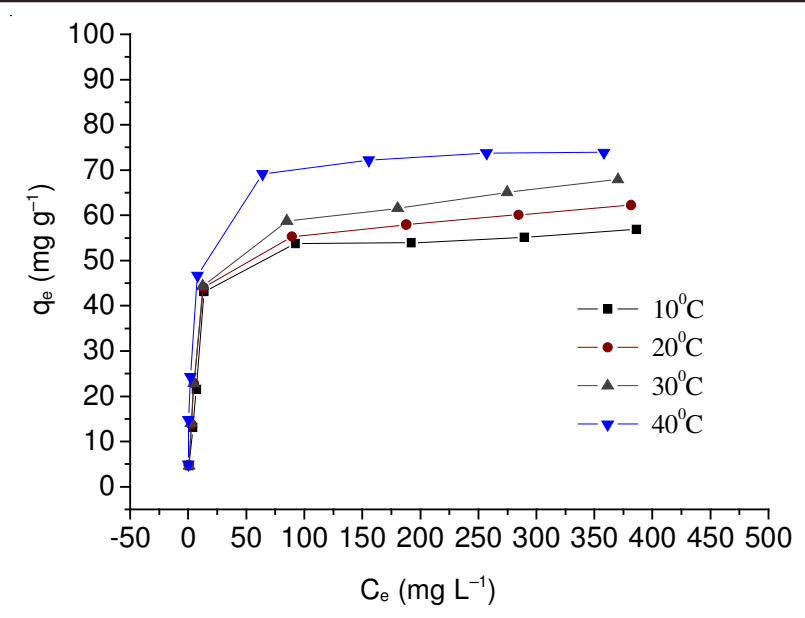

Fig. 3. Plot of $\mathrm{q}_{\mathrm{e}}$ versus $\mathrm{C}_{\mathrm{e}}$ at different temperatures

Freundlich model: The empirical equation of Freundlich can be applied for non-ideal adsorption on heterogeneous surfaces and multilayer adsorption ${ }^{11}$. This model can be written as:

$$
\mathrm{q}_{\mathrm{e}}=\mathrm{K}_{\mathrm{f}} \mathrm{C}_{\mathrm{e}}^{1 / \mathrm{n}}
$$

where $\mathrm{K}_{\mathrm{f}}\left[\left(\mathrm{mg} \mathrm{g}^{-1}\right) /\left(\mathrm{mg} \mathrm{L}^{-1}\right)^{1 / n}\right]$ and $\mathrm{n}$ (dimensionless) are capacity constant and empirical parameter relating to the affinity, respectively.

Parameters of the model were shown in Table-2. The results indicated that the Freundlich model can not adequately describe the isothermal adsorption process since the correlation coefficients were found to be only $0.90-0.97$ and the $1 / \mathrm{n}$ values were ruleless.

Langmuir model: The Langmuir model assumes that adsorption occurs at specific homogeneous sites on the adsorbent and was used successfully in many monolayer adsorption processes. This model can be expressed as follows ${ }^{10}$.

$$
\mathrm{q}_{\mathrm{e}}=\frac{\mathrm{q}_{\mathrm{m}} \mathrm{bC}_{\mathrm{e}}}{1+\mathrm{bC}_{\mathrm{e}}}
$$

where $\mathrm{q}_{\mathrm{m}}\left(\mathrm{mg} \mathrm{g}^{-1}\right)$ is the maximum amount of copper(II) adsorbed on the biomass and $\mathrm{b}\left(\mathrm{L} \mathrm{mg}^{-1}\right)$ is a constant related to the affinity of the binding sites. $\mathrm{q}_{\mathrm{e}}\left(\mathrm{mg} \mathrm{g}^{-1}\right)$ is the adsorption capacity at equilibrium.

The Langmuir plots for copper(II) isothermal adsorption process were shown in Fig. 4 and the adsorption constants were given in Table-2. The data fitted well in the Langmuir equation, as shown by the regression coefficient values $\mathrm{R}$ in the entire concentration range studied. The values of $\mathrm{q}_{\mathrm{m}}$ and $\mathrm{b}$ increased with the rise of temperatures, indicating an endothermic adsorption process in nature.

Dubinin-Radushkevich (D-R) model: In order to distinguish the adsorption mechanism, the Dubinin-Radushkevich

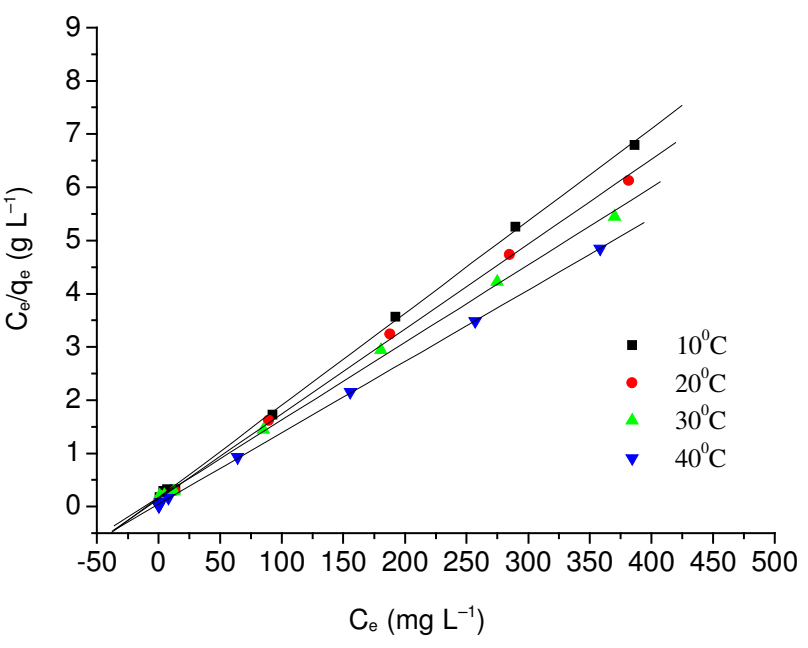

Fig. 4. Linear plots of Langmuir isotherm at different temperatures

model was also analyzed in this study. The D-R equation has the linear form ${ }^{7}$ as follows:

$$
\ln \mathrm{q}_{\mathrm{e}}=\ln \mathrm{q}_{\mathrm{D}}-\beta\left[\mathrm{RT} \ln \left(1+\frac{1}{\mathrm{Ce}}\right)\right]^{2}
$$

where $\mathrm{q}_{\mathrm{D}}$ is theoretical saturation capacity, which can represent the total specific micropore volume of the adsorbent. $\beta$ $\left(\mathrm{mol}^{2} \mathrm{~kJ}^{-2}\right)$ is related to the mean free energy $\left(\mathrm{E}, \mathrm{kJ} \mathrm{mol}^{-1}\right)$ of adsorption per mole of the adsorbate and can be calculated using the relationship ${ }^{7}$ :

$$
E=\frac{1}{\sqrt{2 \beta}}
$$

The parameters of D-R equation are listed in Table-2. The $E$ values in this study were found to be higher than $11 \mathrm{~kJ} \mathrm{~mol}^{-1}$ at all studied temperatures, indicating a chemical ion-exchange process according to the literature.

Thermodynamics of adsorption: The thermodynamic parameters $\left(\Delta \mathrm{G}^{\mathrm{o}}, \Delta \mathrm{H}^{\mathrm{o}}\right.$ and $\left.\Delta \mathrm{S}^{\mathrm{o}}\right)$ were determined by using the following equations:

$$
\begin{aligned}
& \ln \mathrm{b}=\frac{\Delta \mathrm{S}^{\mathrm{o}}}{\mathrm{R}}-\frac{\Delta \mathrm{H}^{\mathrm{o}}}{\mathrm{RT}} \\
& \Delta \mathrm{G}^{\mathrm{o}}=\Delta \mathrm{H}^{\mathrm{o}}-\mathrm{T} \Delta \mathrm{S}^{\mathrm{o}}
\end{aligned}
$$

where $\mathrm{b}$ is Langmuir constant. According to eqn. 6 , the $\Delta \mathrm{H}^{\circ}$ and $\Delta S^{\circ}$ parameters can be calculated from the slope and intercept of the plot of $\ln \mathrm{b}$ versus $1 / \mathrm{T}$ yields, respectively. All the results are recorded in Table- 3 .

The negative $\Delta \mathrm{G}^{\mathrm{o}}$ values indicated thermodynamically

\begin{tabular}{|c|c|c|c|c|c|c|c|c|c|}
\hline \multirow{2}{*}{$\begin{array}{c}\text { Temperature } \\
\text { (K) }\end{array}$} & \multicolumn{3}{|c|}{ Freundlich isotherm } & \multicolumn{3}{|c|}{ Langmuir isotherm } & \multicolumn{3}{|c|}{ D-R isotherm } \\
\hline & $1 / \mathrm{n}$ & $\mathrm{K}_{\mathrm{f}}\left(\mathrm{mg} \mathrm{g}^{-1}\right)$ & $\mathrm{R}$ & $\mathrm{b}\left(\mathrm{L} \mathrm{mg}^{-1}\right)$ & $\mathrm{q}_{\mathrm{m}}\left(\mathrm{mg} \mathrm{g}^{-1}\right)$ & $\mathrm{R}$ & $\mathrm{q}_{\mathrm{m}}\left(\mathrm{mmol} \mathrm{g}^{-1}\right)$ & $\mathrm{E}\left(\mathrm{kJ} \mathrm{mol}^{-1}\right)$ & $\mathrm{R}$ \\
\hline 285 & 8.42 & 0.3712 & 0.9195 & 0.1019 & 56.38 & 0.9998 & 0.75 & 11.6102 & 0.9472 \\
\hline 295 & 9.95 & 0.3501 & 0.9355 & 0.1100 & 61.28 & 0.9997 & 0.74 & 12.4608 & 0.9687 \\
\hline 305 & 9.18 & 0.3786 & 0.9201 & 0.0862 & 69.35 & 0.9994 & 0.95 & 12.1258 & 0.9511 \\
\hline 318 & 18.32 & 0.2778 & 0.9781 & 0.3185 & 75.20 & 0.9999 & 0.72 & 15.3214 & 0.9899 \\
\hline
\end{tabular}
feasible and spontaneous nature of the adsorption. $\Delta \mathrm{G}^{\mathrm{o}}$ values varied from -21.99 to $-28.02 \mathrm{~kJ} \mathrm{~mol}^{-1}$ in the range of $285-318$ $\mathrm{K}$. The results implied that the adsorption of copper(II) onto

TABLE-2

ISOTHERM PARAMETERS FOR THE ADSORPTION OF COPPER(II) ON THE BIOMASS 


\begin{tabular}{|c|c|c|c|c|}
\hline \multicolumn{5}{|c|}{$\begin{array}{c}\text { TABLE-3 } \\
\text { THERMODYNAMIC PARAMETERS FOR THE } \\
\text { ADSORPTION OF COPPER(II) ON THE BIOMASS }\end{array}$} \\
\hline $\begin{array}{l}\text { Temp. } \\
\text { (K) }\end{array}$ & $\begin{array}{c}\mathrm{b} \\
\left(\mathrm{L} \mathrm{mg}^{-1}\right)\end{array}$ & $\begin{array}{c}\Delta \mathrm{G}^{\mathrm{o}} \\
\left(\mathrm{kJ} \mathrm{mol}^{-1}\right)\end{array}$ & $\begin{array}{c}\Delta \mathrm{H}^{\mathrm{o}} \\
\left(\mathrm{kJ} \mathrm{mol}^{-1}\right)\end{array}$ & $\begin{array}{c}\Delta \mathrm{S}^{\mathbf{o}} \\
\left(\mathrm{J} \mathrm{mol}^{-1} \mathrm{~K}^{-1}\right)\end{array}$ \\
\hline 285 & 0.10188 & -21.99 & \multirow{4}{*}{23.02} & \multirow{4}{*}{161.3} \\
\hline 295 & 0.11032 & -23.87 & & \\
\hline 305 & 0.08689 & -25.19 & & \\
\hline 318 & 0.3250 & -28.02 & & \\
\hline
\end{tabular}

F. camelliae was enhanced by high temperature. The positive $\Delta \mathrm{H}^{\mathrm{o}}\left(23.02 \mathrm{~kJ} \mathrm{~mol}^{-1}\right)$ further confirmed the endothermic nature of the adsorption process. The positive $\Delta \mathrm{S}^{\circ}\left(161.3 \mathrm{~J} \mathrm{~mol}^{-1} \mathrm{~K}^{-1}\right)$ was characteristic of increased randomness at the solidsolution interface during the adsorption process ${ }^{1}$. In the adsorption of copper(II), the adsorbate species displaced adsorbed solvent molecules to gain more translational entropy than was lost by the adsorbate ions, thus allowing randomness in the system ${ }^{12}$.

Desorption experiments: Desorption studies were carried out to understand the bonding strength of copper(II) with $F$. camelliae. Deionized water (DW), $\mathrm{HCl}$ solution $(0.5$ mmol $\left.\mathrm{L}^{-1}\right)$ and $\mathrm{NaCl}$ solution $\left(0.5 \mathrm{mmol} \mathrm{L}^{-1}\right)$ were used as eluent. Results were shown in Fig. 5 which indicated that $\mathrm{Pb}$ (II) ions were chemically fixed on the $F$. camelliae other than physical adsorption by electrostatic attraction. For reuse purpose, the adsorbent can be regenerated in acid media.

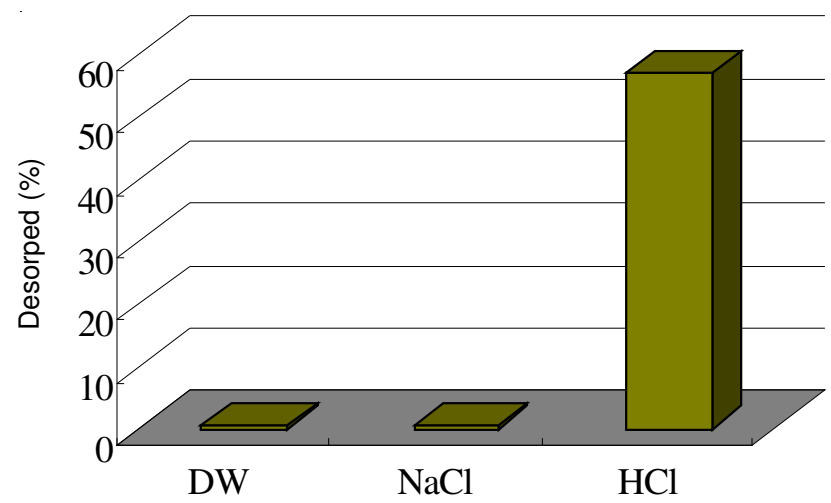

Fig. 5. Effect of eluent type on the desorption percentage

Recovery experiments: In order to reclaim copper(II) from the environment to eliminate pollution completely, the copper(II)-loaded-F. camelliae was incinerated to ash. Nitric acid solution $(2 \% \mathrm{w} / \mathrm{v})$ was added to the ash to dissolve the residue. The solution was then diluted to $50 \mathrm{~mL}$ and assayed with AAS for copper(II) concentration. The average recovery percentage amounted to $96.20 \%$. This result suggested that the removal and reclamation of $\mathrm{Pb}(\mathrm{II})$ from aqueous solution with $F$. camelliae was practical and efficient.

Implication for the tea plant: Based on the above analysis, conclusions can be drawn that $F$. camelliae is an effective adsorbent for the removal of copper(II). It has positive significance in terms of environmental pollution control. However, tea leaves combine with lead readily especially in weak acid conditions, which went against the producing of pollution-free food. Hence, tea garden must be kept away from high way and industrial park. The polluted water should be absolute prohibitions in tea garden irrigation.

\section{Conclusion}

Waste $F$. camelliae is an idea adsorbent for the removal of lead ions from aqueous solutions. Equilibrium data were best described by the Langmuir model. The highest monolayer adsorption capacity was $75.20 \mathrm{mg} \mathrm{g}^{-1}$. The lead adsorption was spontaneous and endothermic in nature and the adsorption process may mainly be chemical ion-exchange mechanism. Acylamide, carbonyl, amino, carboxyl and hydroxyl groups were responsible for the adsorption behavior. copper(II) fixed on F. camelliae can be reclaimed by incineration. It is a sound technique considering the high efficiency, low cost and pollution. On the other hand, it is worthy of being alert about the environment of tea planting garden to prevent the health threat from lead pollution.

\section{REFERENCES}

1. E.A. da Silva, E.S. Cossich and C.R.G. Tavares, Process Biochem., 38, 791 (2002).

2. M.S. Alhakawati and C.J. Banks, J. Environ. Manage., 72, 195 (2004).

3. C.S. Zhu, L.P. Wang and W.B. Chen, J. Hazard. Mater., 168 ( 2009).

4. F.A. Vega, E.F. Covelo and M.L. Andrade, J. Hazard. Mater., 169, 36 (2009).

5. S.S. Majumdar, S.K. Das, T. Saha, G.C. Panda, T. Bandyopadhyoy and A.K. Guha, Colloid. Surf. B: Biointerf, 63, 138 (2008).

6. K. Yetilmezsoy and S. Demirel, J. Hazard. Mater., 153, 1288 (2008).

7. Q.Z. Li, L.Y. Chai, Z.H. Yang and Q.W. Wang, Appl. Surf. Sci., 255, 4298 (2009).

8. Y. Kalmykova, A. Strömvall and B. Steenari, J. Hazard. Mater., 152, 885 (2008).

9. Q. Li, J.P. Zhai and W.Y. Zhang, J. Hazard. Mater, 141, 205 (2007).

10. M.A. Hossain, M. Kumita and Y. Michigami, Adsorption, 11, 5 (2005).

11. A. Zuorro and R. Lavecchia, Am. J. Appl. Sci., 2, 7 (2010).

12. A. Sari, M. Tuzen, O.D. Uluozlu and M. Soylak, Biochem. Eng. J., 37, 151 (2007). 